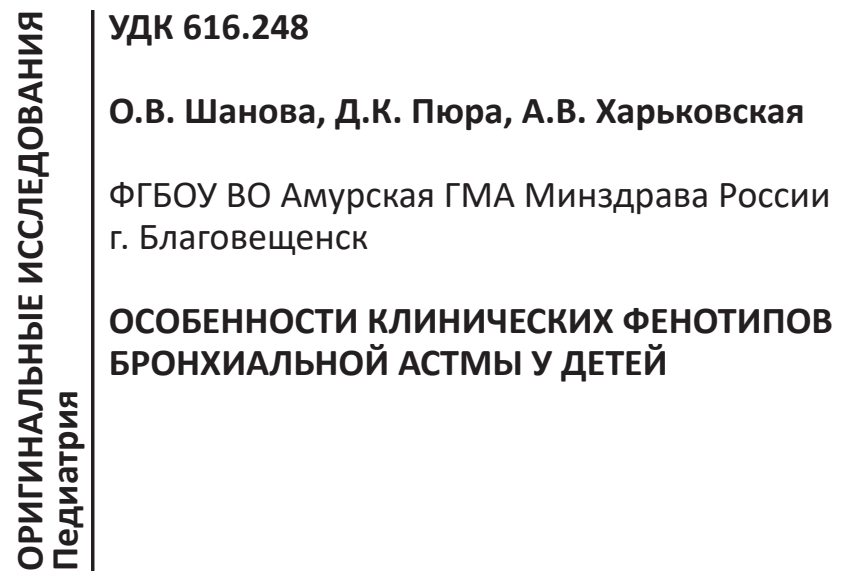

Бронхиальная астма (БА) - распространенное хроническое заболевание органов дыхания у детей характеризуется большой гетерогенностью клиническихформивариабельностьютечения.Являясь сложным и многокомпонентным заболеванием, она так же характеризуется различными фенотипами. Проблемы фенотипирования БА у детей и подростков уже длительное время остаются в фокусе внимания врачей-аллергологов и педиатров. При делении астмы на фенотипы учитывают клинические и морфологические характеристики, значимые триггеры, наличие сопутствующей патологии. Кроме того, важной характеристикой клинических фенотипов являются биологические механизмы, при этом особое внимание обращают на тип воспаления (эозинофильный, нейтрофильный и смешанный). Фенотипическая разница отражается на характере естественного течения, тяжести, риске нежелательных исходов и ответе на проводимую терапию [1, 3]. Определение фенотипических особенностей заболевания является обязательным условием для оптимального контроля заболевания [2].

Целью работы было определение клинических, функциональных и лабораторных особенностей БА у детей и подростков с различными фенотипами.

Материалы и методы Было проведено обследование 44 детей с бронхиальной астмой в возрасте 5-17 лет, находившихся на лечении В педиатрическом отделении ГАУЗ АО ДГКБ г. Благовещенска. В соответствии с возрастным диапазоном были выделены возрастные группы: 0 - 5 лет - 17,4\%, 6 - 12 лет - 43,5\%, старше 12 лет $39,1 \%$ детей. По фенотипам пациенты распределились следующим образом: вирус-ассоциированный - 12 (27,3\%) - I группа, классический аллергический - 19 (43,2\%) - II группа, мультитриггерный - 13 (29,5\%) III группа. Всем пациентам проводилось клиническое, лабораторное и функциональное обследование. Обработку фактических данных осуществляли с помощью программ Statistica 6.0.
Результаты исследования При вирусассоциированном фенотипе средний возраст

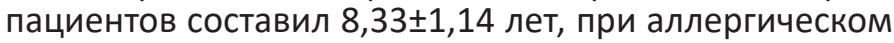

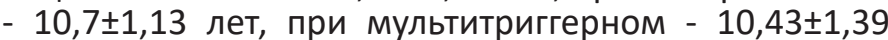
лет. У пациентов I группы заболевание имело преимущественно легкое течение (72,4\%), во II и III группах увеличилась частота средней степени тяжести (46,7\% и 61,5\% соответственно). Более чем у половины детей во всех группах отмечался отягощенный антенатальный анамнез. Острыми респираторными заболеваниями матери детей в сравниваемых группах болели в 33,3\%, 36,8\% и 23,1\% случаев соответственно (p>0,05). Процент недоношенных детей в группах был невысоким. В состоянии легкой асфиксии родилось 16\%, 19,2\% и 20\% детей в трех группах соответственно. Около половины детей этих групп находились на раннем искусственном вскармливании: при вирус-ассоциированном фенотипе - 46,8\%, при аллергическом фенотипе 48,5\%, при мультитриггерном - 49,2\%.

В результате исследования было установлено, что наследственный аллергологический анамнез был отягощен во всех исследуемых группах: у детей с мультитриггерным фенотипом - 69,2\% случаев, т.е. в 2 раза чаще, чем у исследуемых с вирусассоциированным фенотипом - 33,3\% (p<0,05), при классическом аллергическом фенотипе более чем у половины детей и подростков (52,6\%). Среди пациентов с классическим фенотипом аллергическими заболеваниями страдали 57,9\% детей, с вирус-ассоциированным фенотипом - в 2 раза реже - только $25 \%(p<0,05)$. Структура сопутствующей аллергической патологии была представлена атопическим дерматитом, аллергическим ринитом и коньюктивитом. 77,3\% пациентов имели в анамнезе заболевания бронхолегочной системы (частые острые респираторные инфекции, обструктивные бронхиты, пневмонии). Повышение уровня общего IgE отмечалось во всех трех группах (25\%, 47,4\% и 30,8\% соответственно) ( $>>0,05)$. Между первой и второй группами имелись достоверные различия в значениях уровня общего IgE: среднее значение этого показателя у детей с вирус-ассоциированным фенотипом составило 116,55+-46,79, с аллергическим фенотипом $297,37+-61,89$ (р<0,05). Отличия имелись и в характере сенсибилизации. Среди пациентов I группы в качестве триггеров в 4 раза чаще были вирусные инфекции $(p<0,01)$. Статистически достоверных различий в сенсибилизации по бытовым, пищевым и пыльцевым аллергенам у детей II и III групп выявлено не было. Общее количество пациентов с мультитриггерным фенотипом, у которых провоцирующим фактором была физическая нагрузка, составило 30,8\% (в I группе $-8,3 \%$, во II группе - 10,5\%) ( $p<0,05)$. В мазках из зева у обследованных детей I группы в 50\% случаев был
Резюме Бронхиальная астма - самое распространенное хроническое заболевание органов дыхания у детей. Данная статья посвящена фенотипическим особенностям этого заболевания в детском возрасте. Обосновывается целесообразность выделения вирус-ассоциированного, аллергического и мультитриггерного фенотипов, приводится их клинико-лабораторная характеристика. Клинический подход к фенотипированию способствует обеспечению индивидуальной тактики ведения пациентов на этапах динамического наблюдения, выбора терапии и прогнозирования возможного противовоспалительного ответа.

Ключевые слова: бронхиальная астма, фенотипы, дети.

\section{FEATURES OF CLINICAL PHENOTYPES OF BRONCHIAL ASTHMA IN} CHILDREN

O.V. Shanova, D.K. Piura, A.V. Kharkovskaya

FSBEI HE the Amur state medical Academy of Ministry of Public Health of Russia Blagoveshchensk

Abstract Bronchial asthma is the most widespread chronic respiratory disease in children. This article is devoted to phenotypic features of this disease in childhood. Authors of this article have studied the virus-associated, allergic and multitrigger phenotypes and have described clinical and laboratory characteristics. The clinical approach to phenotyping contributes to providing individual tactics of dynamic observation, choice of therapy and predicting a possible antiinflammatory response.

Key words: bronchial asthma, phenotypes, children.

DOI 10.22448/AMJ.2018.4.22-23 
выделен золотистый стафилококк (во II и III группах $21 \%$ и 23,1\% соответственно) ( $<<0,05)$. При анализе частоты выделения золотистого стафилококка в зависимости от возраста пациентов было установлено, что наиболее редко S. aureus определялся $\mathrm{y}$ детей в возрасте 4-5 лет по сравнению со всеми остальными возрастными группами. Носительство этого возбудителя способствует снижению местного иммунитета и оказывает влияние на развитие и клиническое течение астмы.

Анализ результатов ЭКГ-исследования показал, что у детей с изучаемой патологией наблюдались изменения различной степени выраженности и значимости без достоверных различий, представленные преимущественно синусовой тахикардией и обменными нарушениями (при вирусассоциированном фенотипе - 33,3\%, аллергическом фенотипе - 57,8\%, при мультитриггерном фенотипе $30,7 \%)(p>0,05)[4]$.

Обсуждение полученных данных Возраст один из наиболее значимых критериев, определяющих фенотип астмы у детей. Вирус-ассоциированный фенотип представлен группой детей дошкольного возраста, а аллергический и мультитриггерный фенотипы - группой младшего школьного возраста. С увеличением количества триггеров увеличивается степень тяжести заболевания. Более чем у половины детей во всех группах отмечался отягощенный антенатальный анамнез.

Продолжительность грудного вскармливания является важным условием профилактики многих заболеваний. Около половины детей с представленными фенотипами находились на раннем искусственном вскармливании. Наследственный аллергологический анамнез был отягощен во всех исследуемых группах. Не исключено, что мультитриггерный фенотип связан с более сильным атопическим генотипом, так как семейный анамнез при нем регистрировался достоверно чаще $(p<0,05)$. Отмечено, что при вирус-ассоциированном фенотипе дети достоверно реже имели сопутствующую аллергическую патологию и уровень атопии в этой группе был меньше $(p<0,05)$.

Достоверно чаще у пациентов с вирусассоциированым фенотипом выделялся золотистый стафилококк. Носительство этого возбудителя способствует снижению местного иммунитета и оказывает влияние на развитие и клиническое течение астмы. Известно, что между органами дыхания и сердечно-сосудистой системы существует тесная анатомическая и функциональная взаимосвязь. У детей и подростков с БА регистрировались изменения на ЭКГ в виде синусовой тахикардии и обменных нарушений, что свидетельствует о влиянии БА на деятельность сердечно-сосудистой системы.

Заключение Таким образом, выделение фенотипов БА имеет важное значение в медицинской практике. Клинический подход к фенотипированию способствует обеспечению индивидуальной тактики ведения пациентов на этапах динамического наблюдения, выбора терапии и прогнозирования возможного противовоспалительного ответа. Достоверных различий в спектре аритмий при клинических фенотипах бронхиальной астмы не выявлено. Слабость соединительнотканных структур легочной и сердечной тканей предрасполагает к развитию разнообразной патологии органов кардиореспираторной системы, что требует дополнительного изучения признаков дисплазии соединительной ткани, определение особенностей «диспластического фенотипа» у этих больных.

Учитывая сложное взаимодействие между окружающей средой, генетической составляющей и иммунологическими механизмами, участвующими в развитии астмы, наиболее точным представляется междисциплинарный подход к лечению и профилактике этого заболевания.

\section{Литература}

1. Аллергология и иммунология. Национальное руководство / под ред. акад. РАН и РАМН Р.М. Хаитова, проф. Н.И. Ильиной. М.: ГЭОТАР-Медиа, 2009. 649 с.

2. Астафьева Н.Г., Кобзев Д.Ю. Трудности диагностики и лечения бронхиальной астмы у детей первых пяти лет жизни // Лечащий врач. 2011. №1. С. 2127.

Э.Л. Особенности вегетативной реактивности у подростков с бронхиальной астмой с учетом исходного вегетативного тонуса //Материалы VII съезда врачей-пульмонологов Сибири и Дальнего Востока (с международным участием). Благовещенск, 2017. С. 207-210.

4. Шанова О.В. Нарушения ритма сердца у детей с бронхиальной астмой и дисплазиями соединительной ткани //Материалы VII съезда врачей-пульмонологов Сибири и Дальнего Востока (с международным участием). Благовещенск, 2017. С.126-129

Статья поступила в редакцию 04.07.2018

\section{Координаты для связи}

Шанова Оксана Владимировна, к. М. н., ассистент кафедры детских болезней лечебного факультета ФГБОУ ВО Амурская ГМА Минздрава России. E-mail: shanova.oksana@mail.ru

Пюра Дарья Константиновна, студентка 511 группы лечебного факультета ФГБОУ ВО Амурская ГМА Минздрава России. E-mail: dashka16031995@mail.ru

Харьковская Агния Владимировна, студентка 511 группы лечебного факультета ФГБОУ ВО Амурская ГМА Минздрава России. E-mail: agnysha.96@mail.ru

Почтовый адрес ФГБОУ ВО Амурская ГМА Минздрава России: 675000, г. Благовещенск, ул. Горького, 95. E-mail: science.prorector@AmurSMA.su 